\title{
Persuasive Technology for Healthy Aging and Wellbeing
}

\author{
Emmnouil G. Spanakis \\ Institute of Computer Science (ICS) \\ Foundation for Research and \\ Technology (FORTH) \\ Heraklion, Crete, Greece \\ spanakis@ics.forth.gr
}

\author{
Silvina Santana \\ Institute of Electronics Engineering \\ and Telematics of Aveiro (IEETA), \\ University of Aveiro \\ Aveiro, Portugal \\ silvina.santana@ua.pt
}

\author{
Boaz Ben-David \\ Communication Aging and \\ Neuropsychology Lab \\ School of Psychology \\ HERZLIYA, Israel \\ boaz.ben.david@idc.ac.il
}

\author{
Kostas Marias \\ Institute of Computer Science (ICS) \\ Foundation for Research and Technology (FORTH) \\ Heraklion, Crete, Greece \\ kmarias@ics.forth.gr
}

\author{
Chariklia Tziraki MD, $\mathrm{PhD}$ \\ Association of Community Elders' Clubs \\ MELABEV \\ Jerusalem, Israel \\ tziraki@gmail.com
}

\begin{abstract}
In this paper we present key factors for the understanding and acting over behaviors, in order to facilitate healthier aging and wellbeing: motivational theories, health behavioral change theories and physiological constraints of aging. The successful deployment of these related theories can be accomplished through personalized mobile technologies based on behavioral and motivational models that can lead to healthier life styles and sense of well- being throughout an individual's life span.
\end{abstract}

Keywords-mHealth; ehealth; healthy lifestyles; wellbeing; aging; smart phones; intelligent user profiling; activity recognition;

\section{INTRODUCTION}

Chronic diseases, primarily cardiovascular diseases, cancers, chronic respiratory diseases and diabetes, are responsible for $63 \%$ of all deaths worldwide [1]. Chronic disease that account for $80 \%$ of the disease burden continues to rise, driven by the recent explosion in unhealthy lifestyles [2]. Some common denominators have been identified, which can be grouped in the following four interconnected undesirable lifestyle choices: unhealthy eating habits (associated with CVD, obesity, HBP, type II diabetes, cognitive and physical decline), excessive sedentary time/low physical levels (associated with metabolic syndrome, social isolation, depression, cognitive decline), poor stress management (resulting in sleep disorders, anxiety, depression), and lack of meaningful social networks (associate with depression, cognitive decline) [3]. The escalating costs of chronic diseases, and the shrinking healthcare budgets calls for urgent innovative approaches that can be tailored to individual needs and peculiarities and offered independently of geographical situation, in a timely, low cost manner.

Personalized mobile technologies based on behavioral and motivational models may prove to be valuable persuasive tools and mean to foster healthier life styles and sense of wellbeing throughout an individual's life span.

\section{Health AgING AND WellBeing Through ICT}

Development, deployment and evaluation for cost effectiveness of these technologies is currently difficult, mainly due to three key factors: poorly defined methodologies and outcome measures, lack of theory based interventions [4] and, most importantly, insufficient interdisciplinary interaction between the designers of the technology to facilitate health behavioral change and the medo-psychological disciplines to inform the designing of the human interface and the psychosocial theories needed to facilitate wellbeing in an aging population via mobile based technologies. The population at risk has to acknowledge their sensory cognitive and engagement needs. Deteriorated sensory abilities (i.e. vision and hearing) are common and in many studies have shown to impede cognitive processing [5]. Changes in cognitive functions such as attention and executive functions have implications for the mode of conveying the message generating interference from visual distractors [6]. It is important to note that the design that appears engaging for stylists may not be the same for consumers [7].

Persuasive technology and affective computing aim to change peoples' behaviors through persuasion and psychosocial and technological influence. The goal is to put together behavior modification theories \& technology adoption and use theory based evaluation methodologies with clinically meaningful and well defined outcomes, when interventions are delivered through personalized mobile ICT.

\section{REFERENCES}

[1] WHO. Global Health Observatory Data Repository. 2011. http://apps.who.int/ghodata/ (accessed Oct 4, 2011). (2010).

[2] eHealth Task Force Report, Redesigning health in Europe for 2020, ISBN 978-92-79-23542-9, doi:10.2759/82687, 2012.

[3] Dunton GF, et al. (2009). "Using ecological momentary assessment to examine antecedents and correlates of physical activity bouts in adult's age 50+ years: a pilot study." Ann Behav Med 38(3): 249-255.

[4] Webb TL, et. al. "Theoretical Basis, Use of Behavior Change Techniques, and Mode of Delivery on Efficacy." J Med Interner Res 2010;12(1):e4.

[5] Schneider, B., \& Pichora-Fuller, M. K. (2000). Implications of sensory deficits for cognitive aging. In F.I.M. Craik \& T. Salthouse (Eds.), The Handbook of Aging and Cognition (2nd edition), pp.155-219, Mahwah, NJ: Lawrence Erlbaum Associates.

[6] McDowd 1997, Inhibition in attention and aging, Journals of Gerontology Series B-Psychological Sciences \& Social Sciences,52,265-275.

[7] Zimmerman S. et. al. (2011). Cognitive Ageing: a Positive Perspective. In N. Kapur (Ed.), The Paradoxical Brain (130-150). Cambridge University Press. 